\title{
Effect of the Preparation Conditions of a Pd/Si Dual Seedlayer on the Magnetic Properties of Co/Pd Multilayered Perpendicular Magnetic Recording Media
}

\author{
J. Kawaji, T. Asahi", H. Hashimoto, T. Osaka, and K. Asami ${ }^{* *}$ \\ School of Science \& Engineering, Waseda University, 3-4-1 Okubo, Shinjuku-ku, Tokyo 169-8555, Japan \\ "Advanced Research Institute for Science \& Engineering, Waseda University, 3-4-1 Okubo, Shinjuku-ku, Tokyo 169-8555, Japan \\ ${ }^{* *}$ Institute for Material Research, Tohoku University, 2-1-1 Katahira, Aoba-ku, Sendai, Miyagi 980-8577, Japan
}

A Pd/Si dual seedlayer consisting of a 5-nm-thick Pd layer on a 5-nm-thick Si layer was deposited on a substrate prior to the formation of a $[\mathrm{Co} / \mathrm{Pd}]_{n}$ multilayered perpendicular magnetic recording medium, and the effect of the deposition conditions of the dual seedlayer on the magnetic properties of the $[\mathrm{Co} / \mathrm{Pd}]_{n}$ multilayered film was investigated. The addition of $\mathrm{N}_{2}$ to the sputtering Ar gas during the Pd upper seedlayer deposition was effective for decreasing the value of $\alpha$, which is the slope of a perpendicular $M-H$ loop, defined as $4 \pi(\mathrm{d} M / \mathrm{d} H)_{H=H c}$, and reflects the magnitude of intergranular exchange coupling. The value of $\alpha$ was further decreased by post-annealing of the $\mathrm{Pd} / \mathrm{Si}$ dual seedlayer. By combining the effects of $\mathrm{N}_{2}$ addition and the post-annealing in preparing the $\mathrm{Pd} / \mathrm{Si}$ dual seedlayer, both an increase in the reproducing resolution $\left(D_{50}\right)$ and a reduction in the medium noise were achieved. Furthermore, the preparation conditions were found to influence the surface morphology and the state of chemical bonding of the $\mathrm{Pd} / \mathrm{Si}$ dual seedlayer.

Key words: $[\mathrm{Co} / \mathrm{Pd}]_{n}$ multilayer, perpendicular magnetic recording media, $\mathrm{Pd} / \mathrm{Si}$ dual seedlayer, $\mathrm{N}_{2}$ addition, post-annealing, intergranular exchange coupling, medium noise, reproducing resolution, $\mathrm{x}$-ray photoelectron spectroscopy

\section{Introduction}

$\mathrm{Co} / \mathrm{Pd}$ multilayered film (hereafter designated as $[\mathrm{Co} / \mathrm{Pd}]_{n}$, where $n$ is the total number of Co and Pd layers) is a promising candidate for ultra-high-density perpendicular magnetic recording media, because it exhibits strong perpendicular magnetic anisotropy ${ }^{1)}$, which suppresses the decay of magnetization in recorded bits caused by thermal fluctuation. For $[\mathrm{Co} / \mathrm{Pd}]_{n}$ media to be applicable to high-density-recording, it is essential that the medium noise should be reduced by decreasing intergranular exchange coupling while retaining high thermal stability. Magnetic clustering of crystal grains is suppressed by decreasing intergranular exchange coupling ${ }^{2,3)}$, which results in the reduction of medium noise. It is known that the slope of the $M-H$ loop, $\alpha$, which is defined as $4 \pi(\mathrm{d} M / \mathrm{d} H)_{H=H c}$, reflects the magnitude of intergranular exchange coupling ${ }^{2,3)}$, and that the value of $\alpha$ is required to be close to 1 for medium noise reduction, which means that therc is small intergranular exchange coupling. Addition of other elements such as $\mathrm{Cr}-\mathrm{Ta}^{4)}, \mathrm{B}^{5)}$, and $\mathrm{B}-\mathrm{O}^{6)}$ to a Co layer and/or a $\mathrm{Pd}$ layer has been reported to decrease the value of $\alpha$ effectively through the segregation of those elements to grain boundaries. However, it should be noted that the suppression of the value of $\alpha$ by these methods often accompanies a fatal decrease in thermal stability. On the other hand, the use of seedlayers such as $\mathrm{Au}-\mathrm{SiO}_{2}{ }^{6}$, indium-tin-oxide ${ }^{7}, \mathrm{Pd}-\mathrm{SiN}^{8)}, \mathrm{SiO}_{2}{ }^{9}$, and $\mathrm{CoCrRu}{ }^{10)}$ has also been confirmed to reduce the $\alpha$ value of $[\mathrm{Co} / \mathrm{Pd}]_{n}$ media.

The development of a several-nanometer-thick seedlayer is of great significance for fabricating $[\mathrm{Co} / \mathrm{Pd}]_{n}$ film as the recording layer of a double-layered recording medium ${ }^{7-10)}$ with high thermal stability and satisfactory read-write performance. In a previous study, we reported that the value of $\alpha$ for $[\mathrm{Co} / \mathrm{Pd}]_{n}$ single-layered perpendicular media was successfully decreased by using an amorphous $\mathrm{C}$ or $\mathrm{Si}$ seedlayer thicker than $60 \mathrm{~nm}^{11,12)}$. Furthermore, it was revealed that the application of a $\mathrm{Pd}(3 \mathrm{~nm}) / \mathrm{Si}(100 \mathrm{~nm})$ dual seedlayer not only reduced intergranular exchange coupling but also enhanced perpendicular magnetic anisotropy ${ }^{13)}$. However, the $\mathrm{Pd} / \mathrm{Si}$ dual seedlayer should be made as thin as possible so that it is applicable to double-layered perpendicular media.

We aimed at developing a $\mathrm{Pd} / \mathrm{Si}$ dual seedlayer with a thickness of $10 \mathrm{~nm}$ for the $[\mathrm{Co} / \mathrm{Pd}]_{n}$ medium in a preliminary investigation for future studies of double-layered recording media. This paper discusses the effect of the preparation conditions of the $\mathrm{Pd} / \mathrm{Si}$ dual seedlayer, namely, the effect of $\mathrm{N}_{2}$ addition to the sputtering gas and post-annealing of the $\mathrm{Pd} / \mathrm{Si}$ dual seedlayer, on the magnetic properties, especially the $\alpha$ value, of $[\mathrm{Co} / \mathrm{Pd}]_{n}$ films deposited on the seedlayer. The effect of the preparation conditions on the surface state of the $\mathrm{Pd} / \mathrm{Si}$ dual seedlayer is also described.

\section{Experiment}

Thin-film media composed of C (5 nm) / [Co (0.2 nm)/ $\mathrm{Pd}(0.8 \mathrm{~nm})]_{20} / \mathrm{Pd} / \mathrm{Si} /$ substrate were fabricated by $\mathrm{dc}$ magnetron sputtering. A 2.5 -inch-diameter glass disk was used as the substrate for the media except in x-ray photoelectron spectroscopy (XPS) measurements, in which a single-crystal Si (100) wafer was used as the substrate. $\mathrm{The} \mathrm{Pd} / \mathrm{Si}$ dual seedlayer was prepared by depositing a 5-nm-thick layer of Pd onto a 5-nm-thick layer of Si. In this study, the effects of the addition of $\mathrm{N}_{2}$ to Ar sputtering gas during the deposition of the $\mathrm{Pd}$ layer and post-annealing of the $\mathrm{Pd} / \mathrm{Si}$ dual seedlayer deposited at room temperature were examined. On the other hand, a 
$[\mathrm{Co} / \mathrm{Pd}]_{n}$ perpendicular recording layer was deposited at room temperature in an $\mathrm{Ar}$ gas atmosphere for all media. The preparation conditions for the $[\mathrm{Co} / \mathrm{Pd}]_{n}$ media are summarized in Table 1. The magnetic properties of the $[\mathrm{Co} / \mathrm{Pd}]_{n}$ media were measured by using a vibrating sample magnetometer (maximum applied field: $15 \mathrm{kOe}$ ) and a torque magnetometer (maximum applied field: $20 \mathrm{kOe}$ ). The value of $K_{\mathrm{u}}$ was obtained by adding the demagnetization energy $2 \pi M_{\mathrm{s}}{ }^{2}$ to the experimental value determined by means of the torque magnetometer, where $M_{\mathrm{s}}$ is the saturation magnetization. The anisotropy field in the perpendicular direction was obtained by using the following equation:

$$
H_{\mathrm{k}}=2 K_{\mathrm{u}} / M_{\mathrm{s}}
$$

The magnetization states of the media were observed with a magnetic force microscope (MFM) whose tip was coated with a Co alloy. The crystalline microstructure of the $[\mathrm{Co} / \mathrm{Pd}]_{n}$ media was analyzed by $\mathrm{x}$-ray diffraction (XRD) using $\mathrm{Cu}-K_{\alpha}$ radiation at an acceleration voltage of $50 \mathrm{kV}$ and an emission current of $200 \mathrm{~mA}$. The read-write $(\mathrm{R} / \mathrm{W})$ characteristics were investigated by using a merged MR head $\left(B_{\mathrm{s}}=1.5 \mathrm{~T}\right)$ for recording (gap length $g_{1}=0.27 \mu \mathrm{m}$, track width $\mathrm{T}_{\mathrm{w}}=1.45 \mu \mathrm{m}$ ) and reproducing (shield-to-shield gap length $g_{s-s}=0.2 \mu \mathrm{m}$, track width $\mathrm{T}_{\mathrm{w}}=0.9 \mu \mathrm{m}$ ). The linear velocity was set at $6.35 \mathrm{~m} / \mathrm{s}$. The reproduced voltage, $S_{\mathrm{p}-\mathrm{p}}$, was the peak-to-peak signal amplitude measured by using a spectrum analyzer, and the medium noise, $N_{\text {rms, was }}$ evaluated by integrating up to $50 \mathrm{MHz}$ and subtracting the system noise power from the total noise power. The surface morphology of the $\mathrm{Pd} / \mathrm{Si}$ dual seedlayer was

Table 1 Sputtering and post-annealing conditions for the deposition of $[\mathrm{Co} / \mathrm{Pd}]_{n}$ media.

\begin{tabular}{|c|c|c|c|}
\hline \multicolumn{3}{|c|}{ Background pressure } & $<3 \times 10^{-7}$ Torr \\
\hline \multirow{3}{*}{$\begin{array}{c}\text { Ar gas } \\
\text { pressure }\end{array}$} & \multicolumn{2}{|c|}{$[\mathrm{Co} / \mathrm{Pd}]_{n}$ multilayer } & $20 \mathrm{mTorr}$ \\
\hline & \multicolumn{2}{|c|}{$\mathrm{Pd} / \mathrm{Si}$ dual seedlayer } & 100 mTorr \\
\hline & \multicolumn{2}{|c|}{ C overcoat layer } & 50 mTorr \\
\hline \multicolumn{3}{|c|}{$\begin{array}{c}\mathrm{N}_{2} \text { gas pressure } \\
\text { (Pd upper seedlayer deposition) }\end{array}$} & $5 \mathrm{mT}$ orr \\
\hline \multirow{2}{*}{\multicolumn{2}{|c|}{$\begin{array}{l}\text { Post-annealing of } \\
\mathrm{Pd} / \text { Si seedlayer }\end{array}$}} & $\begin{array}{l}\text { Temperature } \\
\text { as monitored }\end{array}$ & $400^{\circ} \mathrm{C}$ \\
\hline & & Time & $20 \mathrm{~min}$. \\
\hline
\end{tabular}

observed by using an atomic force microscope (AFM). The state of chemical bonding in the $\mathrm{Pd} / \mathrm{Si}$ dual seedlayer was evaluated by using XPS.

\section{Results}

\subsection{Magnetic properties}

Table 2 shows the preparation conditions of the $\mathrm{Pd} / \mathrm{Si}$ dual seedlayer and the magnetic properties of four different $[\mathrm{Co} / \mathrm{Pd}]_{20}$ media with the seedlayer (media A-D). The magnetic properties of the $[\mathrm{Co} / \mathrm{Pd}]_{20}$ medium with a 100 -nm-thick Si seedlayer, reported in ref. 11, are also included in Table 2 (medium E). Medium A exhibited a large $\alpha$ value, which indicated the characteristic feature of strong intergranular exchange coupling of the $[\mathrm{Co} / \mathrm{Pd}]_{20}$ film. Medium B, whose $\mathrm{Pd}$ upper seedlayer was deposited in Ar gas containing $\mathrm{N}_{2}$, showed a smaller $\alpha$ value than medium $\mathrm{A}$. By comparing media $\mathrm{A}, \mathrm{B}, \mathrm{C}$, and $D$, it can be stated that the effect of post-annealing of the seedlayer on the $\alpha$ value was significantly influenced by $\mathrm{N}_{2}$ during the $\mathrm{Pd}$ deposition, that is, by whether $\mathrm{N}_{2}$ was added to the $\mathrm{Ar}$ gas or not. Post-annealing of a $\mathrm{Pd} / \mathrm{Si}$ dual seedlayer prepared without $\mathrm{N}_{2}$ addition increased the $\alpha$ value (medium $\mathrm{C}$ ). On the other hand, post-annealing after $\mathrm{Pd} / \mathrm{Si}$ deposition with $\mathrm{N}_{2}$ addition decreased the $\alpha$ value to 2.3 , which was equal to that of medium $E$. These results suggest that intergranular exchange coupling was successfully decreased by combining the effects of $\mathrm{N}_{2}$ addition and post-annealing in the $\mathrm{Pd} / \mathrm{Si}$ dual seedlayer preparation.

Media with a $\mathrm{Pd} / \mathrm{Si}$ dual seedlayer prepared by post-annealing exhibited a strong anisotropy field $\left(H_{\mathrm{k}}\right)$, while media whose Pd upper seedlayer was deposited in an Ar atmosphere containing $\mathrm{N}_{2}$ showed a relatively weak anisotropy field. On the other hand, the perpendicular coercivity $H_{\mathrm{c}}$ tended to be larger for media exhibiting a smaller $\alpha$ value. The maximum value of $5.9 \mathrm{kOe}$ was obtained for medium $\mathrm{D}$, which showed the lowest $\alpha$ value. It was considered that the increase in $H_{\mathrm{c}}$ was due to the change in the magnetic reversal mechanism from wall-motion to rotation magnetization, which was caused by the suppression of intergranular exchange coupling. The same tendency was observed in the case of $[\mathrm{Co} / \mathrm{Pd}]_{20}$ media with an amorphous $\mathrm{C}$ seedlayer ${ }^{14)}$.

Figure 1 shows MFM images of media A, B, C, and D, in an ac-demagnetized state. Figure 2 shows the

Table 2 Preparation conditions of the $\mathrm{Pd} / \mathrm{Si}$ dual seedlayer and magnetic properties of $[\mathrm{Co} / \mathrm{Pd}]_{20}$ media with the dual seedlayer.

\begin{tabular}{|c|c|c|c|c|c|c|c|c|}
\hline Media & Seedlayer & $\begin{array}{c}\mathrm{N}_{2} \text { pressure during } \\
\text { Pd deposition } \\
\text { (mTorr) }\end{array}$ & $\begin{array}{c}\text { Temperature } \\
\text { during } \\
\text { post-annealing } \\
\left({ }^{\circ} \mathrm{C}\right)\end{array}$ & $\begin{array}{c}\alpha \\
(-)\end{array}$ & $\begin{array}{c}M_{s} \\
\left(\mathrm{emu} / \mathrm{cm}^{3}\right)\end{array}$ & $\begin{array}{c}K_{u} \\
\left(10^{6} \mathrm{erg} / \mathrm{cm}^{3}\right)\end{array}$ & $\begin{array}{c}H_{\mathrm{k}} \\
(\mathrm{kUe})\end{array}$ & $\begin{array}{c}H_{\mathrm{c}} \\
(\mathrm{kUe})\end{array}$ \\
\hline $\mathrm{A}$ & \multirow{4}{*}{$\begin{array}{l}\mathrm{Pd}(5 \mathrm{~nm}) \\
/ \mathrm{Si}(5 \mathrm{~nm})\end{array}$} & 0 & - & 6.2 & 360 & 3.9 & 21 & 5.1 \\
\hline B & & 5 & - & 3.8 & 310 & 3.2 & 20 & 4.7 \\
\hline $\mathrm{C}$ & & 0 & 400 & 9.2 & 360 & 5.3 & 29 & 3.3 \\
\hline D & & 5 & 400 & 2.3 & 320 & 3.9 & 24 & 5.9 \\
\hline $\mathrm{E}$ & $\mathrm{Si}(100 \mathrm{~nm})$ & 0 & - & 2.3 & 300 & 2.3 & 16 & 6.0 \\
\hline
\end{tabular}




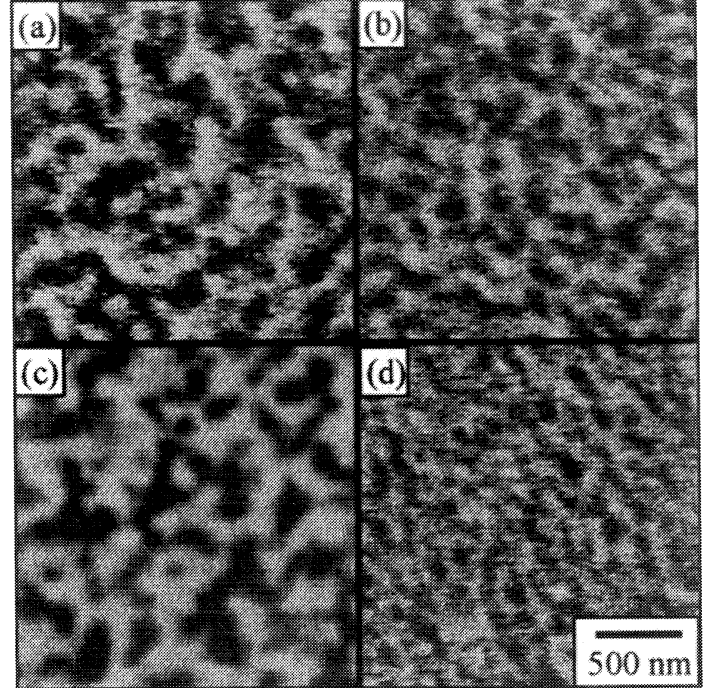

Fig. 1 MFM images of media (a) A, (b) B, (c) C, and (d) $\mathrm{D}$ in the ac-demagnetized state.

correlation of the magnetic domain size obtained from the MFM image with the $\alpha$ value for each medium. To statistically determine the size of magnetic domains with irregular shapes, we drew virtual circles that had the same area as each magnetic domain and calculated their average diameter. It was found that the magnetic domain was finest in the medium showing the smallest $\alpha$ value. It is considered that the suppression of magnetic clustering resulting from the weakened intergranular exchange coupling led to the decrease in magnetic domain size.

\subsection{Microcrystalline structure}

Figure 3 shows XRD patterns for media A, B, C, D, and a glass substrate. The inset in Fig. 3 shows enlarged patterns obtained by subtracting the intensity of the substrate from that of medium B or D. A peak was observed for each medium at $2 \theta=40.7 \mathrm{deg}$., which corresponds to a spacing of 2.22 angstroms. This reflection peak is attributed to fcc-CoPd (111), because the diffraction angle appeared between the $2 \theta$ angles of fcc-Pd (111) and fcc-Co (111), and because the angle for the peak was found to depend on the thickness ratio of Co and Pd layers ${ }^{15)}$. The peak intensities of fcc-CoPd (111) for media B and D were much smaller than those for media $A$ and $C$. This result suggests that $N_{2}$ addition to the sputtering gas during the $\mathrm{Pd}$ deposition resulted in the decrease in the size and/or the degree of [111] preferred orientation of $[\mathrm{Co} / \mathrm{Pd}]_{20}$ crystal grains.

\subsection{Read-write characteristics of $[\mathrm{Co} / \mathrm{Pd}]_{n}$ single- layered perpendicular media}

The reduction of intergranular exchange coupling caused by the $\mathrm{N}_{2}$ addition and the post-annealing of the $\mathrm{Pd} / \mathrm{Si}$ dual seedlayer was considered to affect the $\mathrm{R} / \mathrm{W}$ characteristics of the $[\mathrm{Co} / \mathrm{Pd}]_{n}$ media. In this study, the $\mathrm{R} / \mathrm{W}$ characteristics of media $\mathrm{A}$ and $\mathrm{D}$, whose magnetic properties are shown in Table 2, were compared. Figure

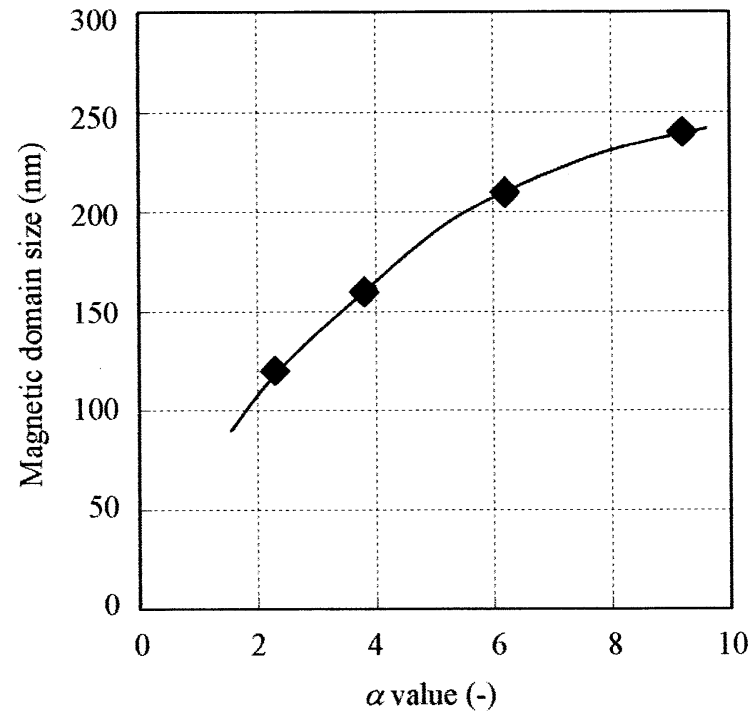

Fig. 2 Correlation between the magnetic domain size and the $\alpha$ value for media A-D.

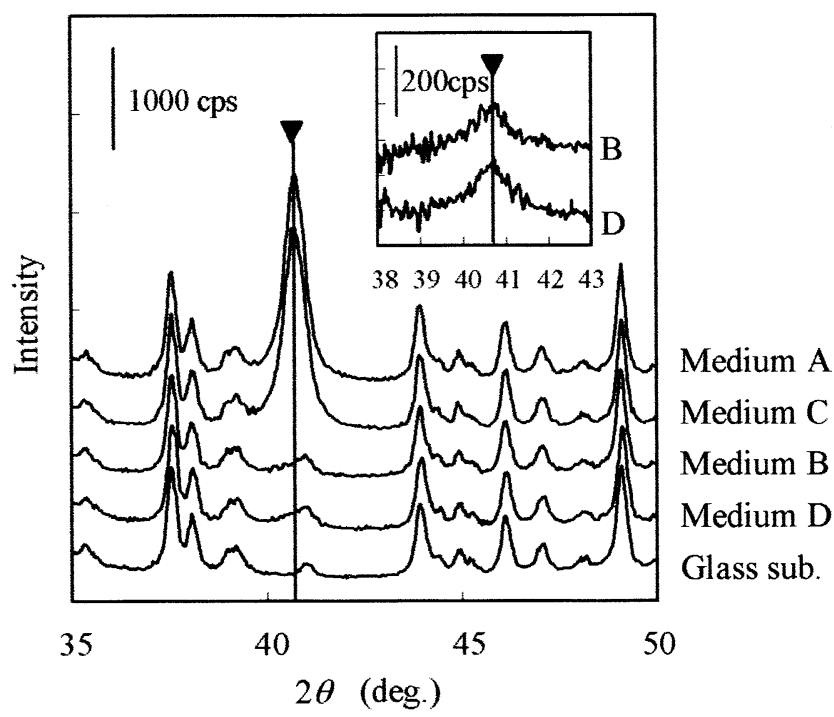

Fig. 3 XRD patterns in media A, B, C, D, and a glass substrate with diffraction angles of $35-50 \mathrm{deg}$. The inset shows patterns obtained by subtracting the diffraction peak of the substrate from that of media B and $\mathrm{D}$. The solid triangle represents a diffraction angle $2 \theta$ of $40.7 \mathrm{deg}$.

4 shows the dependence of the reproduced signal voltage on the recording density for media $\mathrm{A}$ and $\mathrm{D}$, where the reproduced voltage was normalized with respect to the product of the remanent magnetization and the thickness of the recording layer $\left(M_{\mathrm{r}} \delta\right)$. The value of $D_{50}$ of each of the two media is also indicated in Fig. 4. The value of $D_{50}$ is defined as the recording density at which the reproduced voltage is equal to one half of that at $2 \mathrm{kFRPI}$. The normalized reproduced voltage of medium $\mathrm{D}$ was higher than that of medium $\mathrm{A}$ at recording densities greater than 


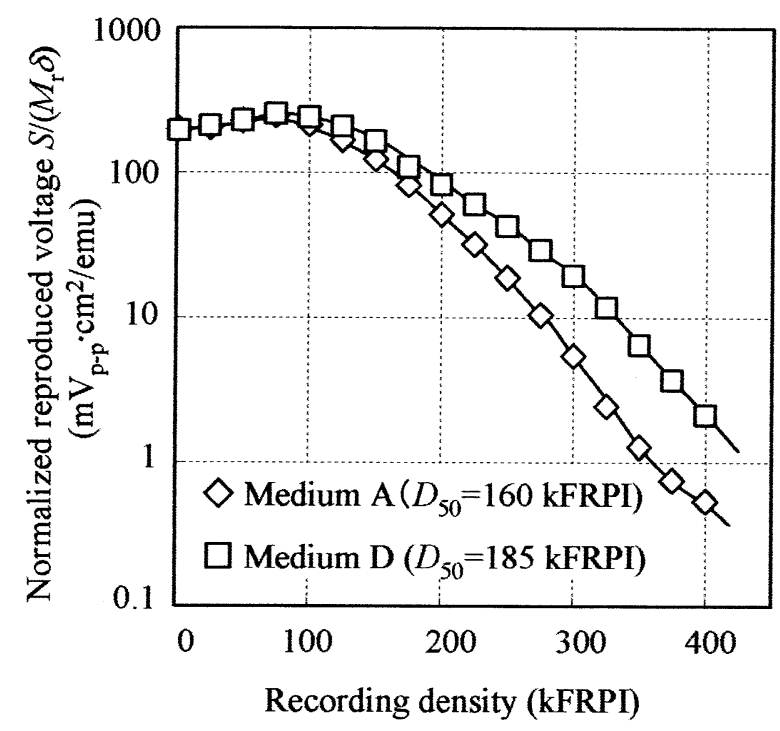

Fig. 4 Dependence of the normalized reproduced voltage on the linear recording density for media $\mathrm{A}$ and D.

$100 \mathrm{kFRPI}$. Medium D showed a higher value of $D_{50}$ than medium A. Figure 5 shows the dependence of the medium noise for media $\mathrm{A}$ and $\mathrm{D}$ on the recording density, where the medium noise of each medium was normalized with respect to the signal at $2 \mathrm{kFRPI}\left(S_{0}\right)$. Medium D showed a lower medium noise than medium $\mathrm{A}$ at all recording densities. Moreover, medium D exhibited a smaller rate of increase in the medium noise with increasing recording density than medium $\mathrm{A}$. It has been pointed out that the increase in medium noise with increasing recording density is mainly caused by the transition noise originating from the fluctuation at the magnetic transition between recorded bits ${ }^{16)}$. Thus, it was considered that the transition noise of medium D was smaller than that of medium A. From the results in Figs. 2,4 , and 5 , it is concluded that the improvement of the reproducing resolution and the suppression of transition noise for medium $\mathrm{D}$ are attributable to the decrease in magnetic cluster size. The signal-to-noise ratio of medium $\mathrm{D}$ was higher by at least $6 \mathrm{~dB}$ than that of medium $A$ at recording densities greater than $100 \mathrm{kFRPI}$.

\subsection{Surface morphology and the state of chemical bonding of the Pd/Si dual seedlayer}

An investigation into the effect of the preparation conditions on the surface state of the $\mathrm{Pd} / \mathrm{Si}$ dual seedlayer was necessary to elucidate the mechanism for the reduction

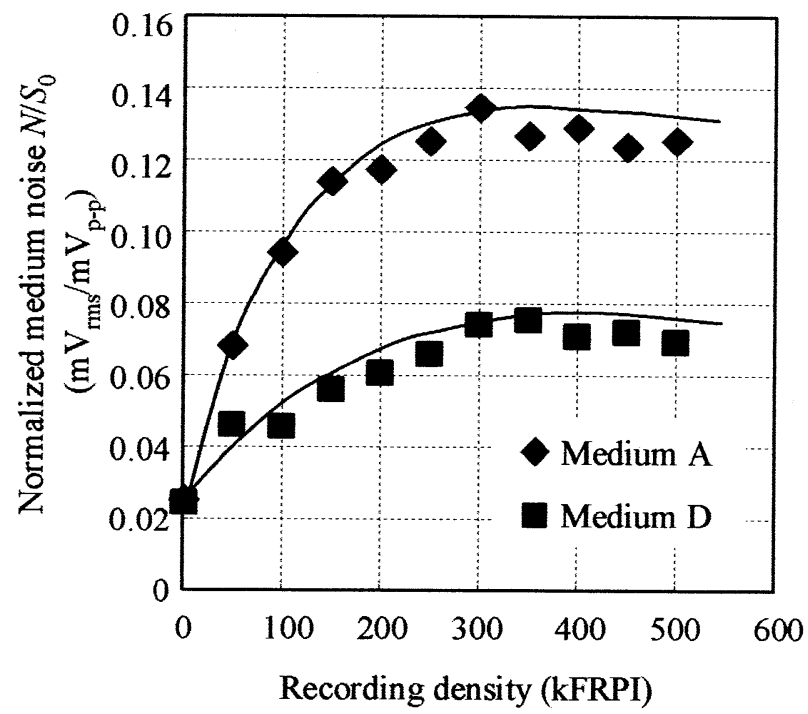

Fig. 5 Dependence of the normalized medium noise on the linear recording density for media $\mathrm{A}$ and $\mathrm{D}$.

of intergranuar exchange coupling brought about by the $\mathrm{Pd} / \mathrm{Si}$ dual seedlayer. In our previous studies ${ }^{15,17)}$, the microstructure of a $[\mathrm{Co} / \mathrm{Pd}]_{20}$ medium with a $\mathrm{C}$ or $\mathrm{Si}$ seedlayer was analyzed, and it was found that the microstructure and magnetic properties of $[\mathrm{Co} / \mathrm{Pd}]_{20}$ media were influenced by the surface roughness of the seedlayer and/or the chemical state at the interface between the $[\mathrm{Co} / \mathrm{Pd}]_{20}$ film and the seedlayer. In this section, the surface roughness and the state of chemical bonding of the $\mathrm{Pd} / \mathrm{Si}$ dual seedlayer are described.

Table 3 shows the root mean square values of the surface roughness $\left(R_{\mathrm{rms}}\right)$ obtained from AFM images of samples I-IV and glass substrate, where samples I-IV are $\mathrm{Pd} / \mathrm{Si}$ films corresponding to the seedlayers for media A-D, respectively. Samples I and III had an identical value of $R_{\mathrm{rms}}$ within the range of experimental error. On the other hand, the values of $R_{\text {rms }}$ for samples II and IV, whose Pd layers were deposited in Ar gas containing $\mathrm{N}_{2}$, were larger than those for samples I and III, with sample II exhibiting the largest value of $R_{\text {rms. }}$ It was reported that the intergranular exchange coupling of a $[\mathrm{Co} / \mathrm{Pd}]_{n}$ medium with a $\mathrm{C}$ seedlayer ${ }^{15)}$ and that of $[\mathrm{CoB} / \mathrm{Pd}]_{n}$ medium with a $\mathrm{SiO}_{2}$ seedlayer" decrease with increasing surface roughness of the seedlayers. However, no quantitative correlation was found in this study between the increase in surface roughness of the seedlayers (Table 3 ) and the

Table 3 Surface roughnesses of various $\mathrm{Pd} / \mathrm{Si}$ dual seedlayers.

\begin{tabular}{c|c|c}
\hline Sample & Preparation of Pd/Si films & Surface roughness $R_{\mathrm{rms}}[\mathrm{nm}]$ \\
\hline I & As sputtered & $0.54 \pm 0.05$ \\
\hline II & $\mathrm{N}_{2}$ addition & $0.94 \pm 0.04$ \\
\hline III & Post-annealing & $0.60 \pm 0.04$ \\
\hline IV & $\mathrm{N}_{2}$ addition + post-annealing & $0.73 \pm 0.01$ \\
\hline \multicolumn{2}{c}{ Glass substrate } & $0.44 \pm 0.03$ \\
\hline
\end{tabular}




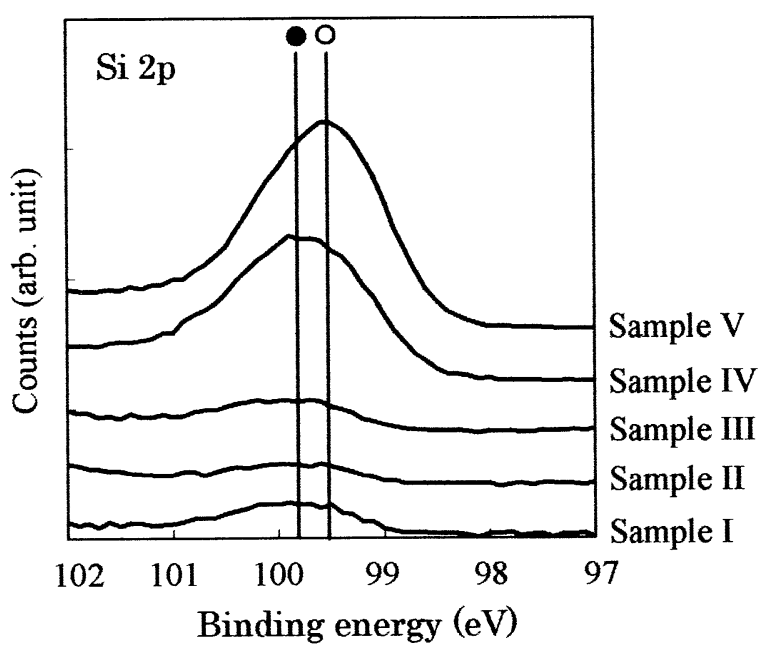

Fig. $6 \mathrm{Si} 2 \mathrm{p}$ photoelectron spectra of samples I, II, III, IV, and V. Sample V is a 5-nm-thick Si film deposited on a Si (100) wafer. The open and solid circles denote the Si $2 p$ electron binding energies of $\mathrm{Si}$ and metal silicide, respectively.

reduction of the $\alpha$ value of the $[\mathrm{Co} / \mathrm{Pd}]_{n}$ film. Medium B, with the largest seedlayer surface roughness, did not exhibit the smallest value of $\alpha$ for the media. Thus, the dependence of the $\alpha$ value on the preparation conditions for the $\mathrm{Pd} / \mathrm{Si}$ dual seedlayer cannot be explained in terms of the surface roughness alone.

Figures 6 and 7 show XPS spectra of Si $2 p$ and Pd $3 d_{5 / 2}$ regions of $\mathrm{Pd} / \mathrm{Si}$ dual seedlayers, respectively. In these XPS experiments, a single-crystal Si substrate was used. It was assumed that the difference between the $\mathrm{Si}$ and the glass substrates was negligible, because it was confirmed that the effect of the preparation conditions of the $\mathrm{Pd} / \mathrm{Si}$ dual seedlayer on the $\alpha$ value of a $[\mathrm{Co} / \mathrm{Pd}]_{n}$ medium deposited on a Si substrate was quite similar to their effect on the $\alpha$ value of the same medium deposited on a glass substrate. Figure 6 shows photoelectron spectra of Si $2 p$ regions for samples $\mathrm{I}-\mathrm{IV}$ and sample $\mathrm{V}$. Sample $\mathrm{V}$ is composed of an amorphous $\mathrm{Si}(5 \mathrm{~nm})$ layer and a $\mathrm{Si}$ substrate. The open and solid circles in Fig. 6 indicate the binding energies attributed to $\mathrm{Si}$ and a metal-silicide compound $^{18)}$, respectively. The XPS peaks for samples I-IV are seen at the binding energy of $c a$. $99.8 \mathrm{eV}$, which is higher than that of sample $\mathrm{V}(99.5 \mathrm{eV})$. These results imply that palladium silicide is formed at the interface between the $\mathrm{Pd}$ and $\mathrm{Si}$ layers in samples I-IV. Figure 7 shows photoelectron spectra of the $\mathrm{Pd} 3 \mathrm{~d}_{5 / 2}$ region for samples III and IV. The open and solid triangles show the $\mathrm{Pd} 3 \mathrm{~d}_{5 / 2}$ electron binding energies of $\mathrm{Pd}$ and $\mathrm{Pd}_{2} \mathrm{Si}$, respectively ${ }^{18)}$. The XPS of $3 \mathrm{~d}_{5 / 2}$ spectra for the samples were measured before and after Ar-ion etching at $1 \mathrm{kV}$. Before Ar-ion etching, the XPS peak positions for samples III and IV were essentially the same, while they were quite different from each other after Ar-ion etching. Namely, the XPS peak originating from the $\mathrm{Pd}_{2} \mathrm{Si}$, which is shown

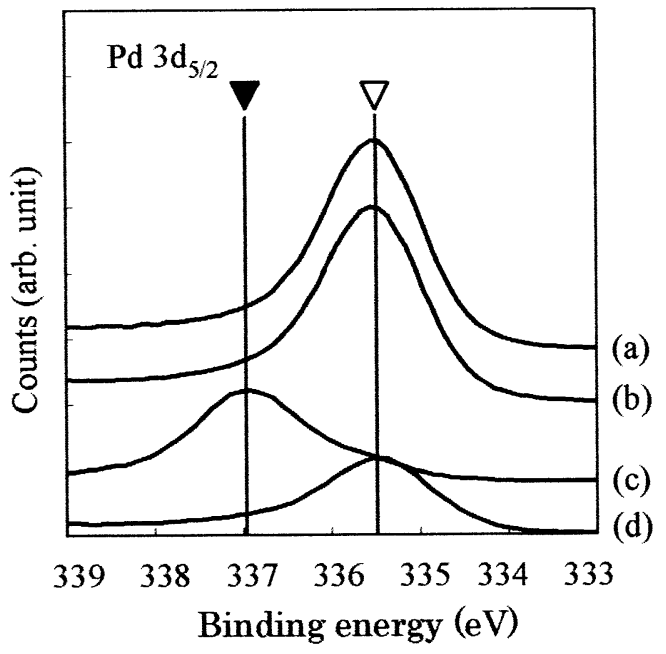

Fig. $7 \mathrm{Pd} 3 \mathrm{~d}_{5 / 2}$ photoelectron spectra of samples III (a, b) and IV (c, d). (a) and (c) are spectra of Ar-ion etched samples, while (b) and (d) are those of samples before Ar-ion etching. The open and solid triangles denote the $\mathrm{Pd} 3 \mathrm{~d}_{5 / 2}$ electron binding energies of $\mathrm{Pd}$ and $\mathrm{Pd}_{2} \mathrm{Si}$.

by the solid triangle in Fig. 7, was clearly observed with sample IV, while this peak was absent in the spectrum for sample III. This result suggests that the post-annealing for the $\mathrm{Pd} / \mathrm{Si}$ dual seedlayer deposited in the presence of $\mathrm{N}_{2}$ markedly promotes the change in the state of chemical bonding between $\mathrm{Pd}$ and $\mathrm{Si}$ in the $\mathrm{Pd} / \mathrm{Si}$ dual seedlayer. In XPS measurements of the $\mathrm{N}$ 1s photoelectron region, a small amount of $\mathrm{N}$ was detected in samples II and IV whose Pd upper seedlayers were deposited in the presence of $\mathrm{N}_{2}$. However, no explicit XPS peak attributable to palladium nitride or silicon nitride was detected in the present experiment.

\section{Discussion}

The present study revealed that $\mathrm{N}_{2}$ addition and post-annealing during the preparation of the $\mathrm{Pd} / \mathrm{Si}$ dual seedlayer were effective for reducing intergranular exchange coupling in $[\mathrm{Co} / \mathrm{Pd}]_{n}$ media, leading to an improvement in $\mathrm{R} / \mathrm{W}$ characteristics. In this section, the effects of the $\mathrm{N}_{2}$ addition and the post-annealing are discussed on the basis of the results of XRD (Fig. 3) and XPS (Figs. 6 and 7).

\subsection{Effect of $\mathbf{N}_{\mathbf{2}}$ addition to sputtering gas}

Many studies on the addition of $\mathrm{N}_{2}$ to sputtering gas have been performed in the past. According to several reports, $\mathrm{N}_{2}$ reacts with sputtered metal atoms to form nitrides such as $\mathrm{FeN}^{19)}$ and $\mathrm{AlN}^{20)}$ in the deposited films. Matsunuma et $a l^{8)}$ reported that a $\mathrm{Pd}-\mathrm{SiN}$ layer, which was prepared by co-sputtering $\mathrm{Pd}$ and $\mathrm{Si}$ in an $\mathrm{Ar}$ gas atmosphere containing $\mathrm{N}_{2}$, was useful as a seedlayer for $[\mathrm{Co} / \mathrm{Pd}]_{n}$ media. In this study, no explicit XPS peaks attributable to the formation of palladium nitride or silicon nitride were detected. However, more precise investigations based on XPS depth profiles are necessary 
to derive a definite conclusion as to whether nitride compounds are formed or not in media B and D. On the other hand, it has been reported that the presence of $\mathrm{N}_{2}$ in sputtering gas prevents grain growth in sputtered films 21, 22). In view of the previous reports described above and the results obtained in the present XPS experiment, it can be considered that the $\mathrm{N}_{2}$ addition contributed to the impeding of crystal grain growth of Pd in the Pd upper seedlayer. This conclusion is supported by the result of XRD (Fig. 3). Namely, in the case of media B and D, a $\mathrm{Pd}$ upper seedlayer with small grains obtained as a result of with $\mathrm{N}_{2}$ addition during sputtering led to a decrease in the grain size of the $[\mathrm{Co} / \mathrm{Pd}]_{n}$ film deposited onto the $\mathrm{Pd}$ upper seedlayer, which weakened the peak intensity of fcc-CoPd (111), as shown in Fig. 3. Furthermore, it was found that the surface roughnesses of the samples deposited in the presence of $\mathrm{N}_{2}$ were greater than those of the samples prepared without $\mathrm{N}_{2}$ addition (Table 3). The degree of preferred orientation of media $B$ and $D$ seems to be lower than that of media $\mathrm{A}$ and $\mathrm{C}$, which can also cause a decrease in the peak intensity of fcc-CoPd (111).

\subsection{Effect of post-annealing of a $\mathrm{Pd} / \mathrm{Si}$ dual seedlayer}

It has been reported that Pd deposited onto a $\mathrm{Si}$ wafer by vacuum evaporation diffused into the wafer and formed a palladium silicide phase when the sample was annealed ${ }^{23)}$. Thus, it is likely that post-annealing of $\mathrm{Pd} / \mathrm{Si}$ dual seedlayer promoted interdiffusion and reaction between $\mathrm{Pd}$ and $\mathrm{Si}$ in samples III and IV.

From the result shown in Fig. 7, it can be seen that interdiffusion and reaction between $\mathrm{Pd}$ and $\mathrm{Si}$ was enhanced by both the effect of $\mathrm{N}_{2}$ addition in the deposition of $\mathrm{Pd}$ and the post-annealing of the $\mathrm{Pd} / \mathrm{Si}$ dual seedlayer. The $[\mathrm{Co} / \mathrm{Pd}]_{20}$ film deposited onto the $\mathrm{Pd} / \mathrm{Si}$ dual seedlayer, where the formation of a palladium silicide phase was most efficiently promoted, exhibited the smallest $\alpha$ value (medium D). In our previous study on $[\mathrm{Co} / \mathrm{Pd}]_{20}$ media with a 100 -nm-thick $\mathrm{Si}$ seedlayer (medium $\mathrm{E}$ in Table 2) showing $\alpha$ values as small as 2.3 , it was revealed that $\mathrm{Pd}_{2} \mathrm{Si}$ phase was formed in the region between the $[\mathrm{Co} / \mathrm{Pd}]_{20}$ film and the $\mathrm{Si}$ seedlayer ${ }^{17}$. The previous and present results led us to conclude that the formation of palladium silicide is relevant to the reduction of intergranular exchange coupling in $[\mathrm{Co} / \mathrm{Pd}]_{n}$ media.

\subsection{Proposed model for the grain growth of $[\mathrm{Co} / \mathrm{Pd}]_{n}$ media deposited on a Pd/Si dual seedlayer}

In accordance with the above discussions, we present a schematic illustration of our model for the grain growth of media A-D in Figs. 8(a)- 8(d). In both media A and B, the $\mathrm{Pd}$ upper seedlayer partially reacts with $\mathrm{Si}$ in the vicinity of the interface between the two seedlayers, while the Pd upper seedlayer of medium B has smaller crystal grains and a rougher surface than that of medium $A$, which is caused by the $\mathrm{N}_{2}$ addition during the $\mathrm{Pd}$ deposition (Figs. 8(a) and 8(b)). The increase in the surface roughness of the $\mathrm{Pd} / \mathrm{Si}$ dual seedlayer leads to a slight lowering of the degree of preferred orientation of the $[\mathrm{Co} / \mathrm{Pd}]_{n}$ film, which causes the grains in the $[\mathrm{Co} / \mathrm{Pd}]_{n}$ film of medium B to be more clearly separated from each other than those of medium A. These are the reasons that the $\alpha$ value of medium B is smaller than that of medium A. On the other hand, the $\mathrm{Pd} / \mathrm{Si}$ dual seedlayer for medium $\mathrm{C}$ is likely to be more extensively reactive as a result of the post-annealing. However, the post-annealing can promote the grain growth in the Pd upper seedlayer at the same time, leading to the formation of a strongly exchange-coupled $[\mathrm{Co} / \mathrm{Pd}]_{n}$ columnar structure with large grains. Therefore, medium C exhibits the largest $\alpha$ value.

Finally, a mechanism by which the smallest $\alpha$ value was obtained with medium $D$ is proposed as follows. As in the case of medium B, the Pd upper seedlayer of medium $D$ affected by the $\mathrm{N}_{2}$ addition consists of smaller grains with more widely spaced grain boundaries than those of media $\mathrm{A}$ and $\mathrm{C}$. Therefore, $\mathrm{Si}$ easily diffuses into $\mathrm{Pd}$ grains and grain boundaries in the Pd upper seedlayer during the post-annealing. Most of the $\mathrm{Si}$ atoms diffusing into and on the Pd grains react with Si to form a palladium silicide phase. As a result, the $\mathrm{Pd} / \mathrm{Si}$ dual seedlayer has a well-defined granular structure composed of Pd-rich silicide crystal grains and $\mathrm{Si}$-rich grain boundaries. When a $[\mathrm{Co} / \mathrm{Pd}]_{n}$ film grows on the granular seedlayer, the palladium silicide crystal grains serve as fine (a) Medium A

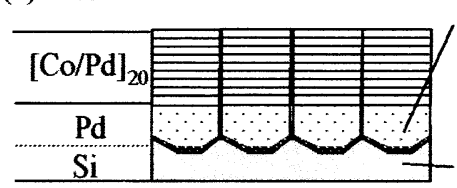

(b) Medium B

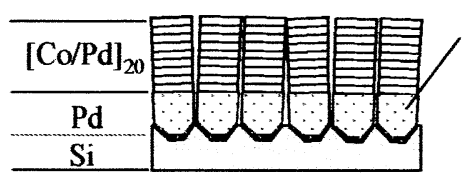

(c) Medium $\mathrm{C}$ $\mathrm{Pd}$ grains containing
regions which reacted
with $\mathrm{Si}$ at the interface
of the $\mathrm{Pd}$ and $\mathrm{Si}$ layers
Amorphous $\mathrm{Si}$

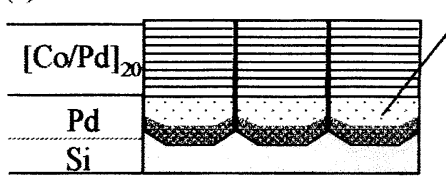

Pd grains with a phase partially reacted with $\mathrm{Si}$ in the region beyond the interface of the Pd and Si layers.

\section{(d) Medium D}

Small Pd grains with rough surface containing regions which reacted with $\mathrm{Si}$ at the interface of the $\mathrm{Pd}$ and Si layers.

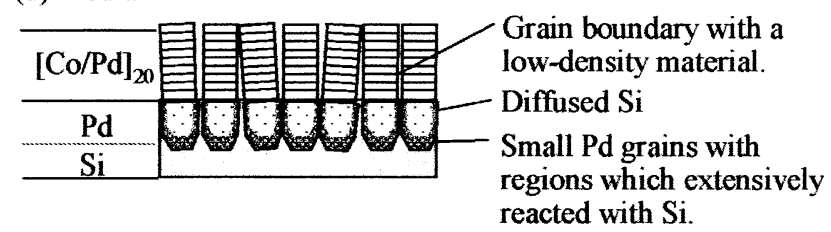

Fig. 8 Schematic representation of our models for media (a) A, (b) B, (c) C, and (d) D. 
nucleation sites and produce a magnetically isolated $[\mathrm{Co} / \mathrm{Pd}]_{n}$ columnar structure, as shown in Fig. 8(d). It is natural to suggest that such a columnar structure of $[\mathrm{Co} / \mathrm{Pd}]_{n}$ film leads to a small $\alpha$ value, although a cross-sectional transmission electron microscope observation should be carried out to verify the validity of this suggestion. On the basis of the results presented above, we claim that the $\mathrm{Pd} / \mathrm{Si}$ dual seedlayer developed in this study has a high potential as an intermediate layer of $[\mathrm{Co} / \mathrm{Pd}]_{n}$ double-layered media.

\section{Conclusions}

A 10-nm-thick $\mathrm{Pd} / \mathrm{Si}$ dual seedlayer was applied in the fabrication of a $[\mathrm{Co} / \mathrm{Pd}]_{n}$ multilayered perpendicular magnetic recording medium. The effect of the preparation conditions of the $\mathrm{Pd} / \mathrm{Si}$ dual seedlayer on the magnetic properties, crystalline microstructure, and read-write characteristics of the $[\mathrm{Co} / \mathrm{Pd}]_{n}$ multilayered media were investigated. It was revealed that the $\alpha$ value was markedly decreased by adding $\mathrm{N}_{2}$ to the sputtering gas during the $\mathrm{Pd}$ upper seedlayer deposition and by post-annealing of the $\mathrm{Pd} / \mathrm{Si}$ dual seedlayer. The $[\mathrm{Co} / \mathrm{Pd}]_{n}$ media exhibiting a low $\alpha$ value showed high reproducing resolution and low medium noise because of a small magnetic cluster size. It was found that $\mathrm{N}_{2}$ addition and post-annealing promoted the interdiffusion and the reaction of $\mathrm{Pd}$ and $\mathrm{Si}$, which apparently caused the formation of a seedlayer desirable for the production of magnetically decoupled $[\mathrm{Co} / \mathrm{Pd}]_{n}$ grains.

\section{Acknowledgements}

The work was carried out at the Center for "Practical Nano-Chemistry" in the 21C-COE Programme and was financially supported by a grant-in-aid for Center of Excellence Research on "Establishment of Molecular Nano-Engineering by Utilizing Nanostructure Arrays and Its Development into Micro-Systems" from the Ministry of Education, Culture, Sports, Science, and Technology, Japan. The authors express their gratitude to Dr. K. Tagami and Mr. N. Oshima of NEC Corporation for their cooperation in torque measurements. The authors also express their gratitude to Prof. J. Hokkyo and Dr. Y. Okinaka of Waseda University for their helpful advice on preparing the manuscript

\section{References}

1) P. F. Carcia, A. D. Meinhaldt, and A. Suna: Appl. Phys. Lett., 178, 47 (1985).
2) I. Tagawa, A. Takeo, and Y. Nakamura: J. Magn. Magn. Mater., 155, 341 (1996).

3) E.Miyashita, R.Taguchi, N.Funabashi, T.Tamaki, and H.Okuda: IEEE Trans. Magn., 38, 2075 (2002).

4) G. Chen: J. Appl. Phys., 87, 6887 (2000).

5) T.Shimatsu, M. Terakawa, I. Watanabe, H. Muraoka, and Y. Nakamura: J. Magn. Soc. Jpn., 219, 26 (2002).

6) H. Ohmori and A. Maesaka: J. Magn. Magn. Mater., 235, 45, (2000).

7) W. Peng, R. H. Victora, J. H. Judy, K. Gao, and J. M. Sovertsen: J. Appl. Phys., 87, 6358 (2000).

8) S. Matsunuma, A. Yano, E. Fujita, T. Onuma, T. Takayama, and N. Ota: IEEE Trans. Magn, 38, 1622 (2002).

9) K. Shimoda, R. Inamura, T. Uzumaki, and A. Tanaka: Digest of 25th Annual Conference on Magnetics in Japan, Akita, Japan, 2001, p. 2.

10) Y. Kubota, D. Weller, M.-L. Wu, X. Wu, G. Ju, D. Karns, and J. Yu: J. Magn. Magn. Mater., 242-245, 297 (2002).

11) T. Onoue, J. Kawaji, K. Kuramochi, T. Asahi, and T. Osaka: J. Magn. Magn. Mater, 235, 82 (2001).

12) T. Onoue, T. Asahi, K. Kuramochi, J. Kawaji, T. Homma, and T. Osaka: J. Magn. Magn. Mater., 235, 40 (2001).

13) J. Kawaji, T. Asahi, T. Onoue, J. Sayama, J. Hokkyo, and T. Osaka: J. Magn. Magn. Mater., 251, 220 (2002).

14) T. Asahi, K. Kuramochi, J. Kawaji, T. Onoue, and T. Osaka, Digest of 5th PMRC, Sendai, Japan, 2000, p. 43.

15) T. Asahi, K. Kuramochi, J. Kawaji, T. Onoue, T. Osaka, and M. Saigo: J. Magn. Magn. Mater., 235, 87 (2001).

16) L. Wu, N. Honda, and K. Ouchi: IEEE Trans. Magn., 37, 2775 (1999).

17) T. Onoue, T. Asahi, K. Kuramochi, J. Kawaji, T. Osaka, J. Ariake, K. Ouchi, G. Safran, and N. Yaguchi: J. Appl. Phys.,92, 4545 (2002).

18) J. F. Moulder, W. F. Stickle, P. E. Sobol, and K. D. Bonben: Handbook of X-ray Photoelectron Spectroscopy, J.Chastain, p. 234 (Perkin-Elmer, Eden Prairie, 1992).

19) S. C. Byeon, F. Liu, and G. J. Mankey: IEEE Trans. Magn., 37, 1770 (2001).

20) K. Kakizaki, H. Watanabe, and N. Hiratsuka: J. Magn. Magn. Mater., 235, 169 (2001).

21) Y. Sano, H. Muraoka, I. Watanabe, and Y. Nakamura: $J$. Magn. Magn. Mater., 155, 212 (1996).

22) K. Kurasawa, M. Kawakami, T. Onoue, T. Asahi, T. Homma, and T. Osaka: Abstracts of Annual Conference of IEICE, Hiroshima, Japan, 2000, 7-C-21.

23) S. Okada, K. Oura, T. Hanawa, and K. Satomi: Surf. Sci., 97 , 88 (1980).

(Received, Sept. 2, 2002; Accepted, Jan. 17, 2003.) 